\title{
The Triad of Science Foundations, Instructional Technology, and Organizational Structure
}

\author{
E.A. Vargas \\ B.F. Skinner Foundation
}

\begin{abstract}
Over the centuries and across all societies educational achievement does not improve. The attempt to improve the instructional process has concentrated on instructional technology. But these attempts have overlooked the importance of two other factors: the science that should underlie the instructional technologies and the organization that must operate those technologies. A considerable step forward in handling the problems of instructional effectiveness has been the derivation of instructional technologies based on Skinnerian science. But the instructional technologies based on Skinner's analysis of behavior are promoted as if they were to operate in an organizational vacuum. The division of labor, and its necessary coordination and control, is taken for granted. But in any large scale enterprise, the organization of the division of labor must fit the technology through which that enterprise achieves its mission. Educational technology must tie directly to a pertinent science and to a proper organizational structure. To teach effectively requires an overhaul along three lines: 1) a relevant science that reflects and encapsulates an accurate understanding of behavior; 2) a contingency-based technology of instruction that directly derives its practices upon proper scientific principles; and 3) a suitable organization based on teaching teams that operate the new instructional technology.
\end{abstract}

Keywords: Instructional Technology, Organizational Structure, Skinner

\begin{abstract}
A lo largo de los siglos y en todas las sociedades la educación no ha avanzado. Los intentos de mejorar el proceso de instrucción se han concentrado en la tecnología de la instrucción. Pero estos intentos no han tenido en cuenta la importancia de otros dos factores: la ciencia que debería fundamentar las tecnologías de la instrucción y la organización que utiliza esas tecnologías. Un importante paso adelante en el manejo de los problemas de la eficacia instruccional ha sido la formulación de tecnologías de la instrucción basadas en la ciencia skinneriana. Sin embargo, las tecnologías de la instrucción basadas en el análisis de la conducta skineriano se promueven como si hubieran de operar en un vacío organizacional. La división del trabajo, y su necesaria coordinación y control, se dan por supuestas. Pero en cualquier proyecto a gran escala, la organización de la división del trabajo debe ajustarse a la tecnología mediante la cual ese proyecto cumple su misión. La tecnología educacional debe ligarse directamente a una ciencia pertinente y a una estructura organizativa adecuada. Enseñar eficazmente requiere una reforma en tres direcciones: 1) una ciencia relevante que refleje y encapsule una comprensión adecuada de la conducta; 2) una tecnología de la instrucción basada en la contingencia que derive su práctica de principios científicos correctos; y 3) una organización adecuada basada en equipos docentes que empleen la nueva tecnología de la instrucción. Palabras clave: Tecnología de la Instrucción, Estructura organizacional, Skinner
\end{abstract}

An earlier version was delivered as an invited address at: Sixth International Congress on Behaviorism and the Sciences of Behavior. Auburn, Alabama, USA September 18-21, 2002.

Correspondence concerning this article should be addressed to E.A. Vargas, B.F. Skinner Foundation, 12 Arrow St. \# 303, Cambridge, MA, 02138, United States. E-mail: eav222nets@ netscape.net 
And mysteries

are like the sun, dazzling, yet plain to all eyes.

John Donne (1633/1991)

We get no closer to solving our primary educational mystery - that of teaching well. Despite the patronage, despite the support, despite the exertions, and despite the complaints, criticisms, and constant demands that education reinvent itself and despite the dictates on how that reinvention should occur, the effectiveness and efficiency of school systems throughout the world remain at their usual modest level. Oh, here or there, a bright spot sparkles. But the occasional happy accident provides no solution for the mundane modus operandi of other educational institutions. If it did, what school would not adopt what works elsewhere? Such happy accidents result from circumstances not replicable elsewhere; an outcome that proponents of voucher systems overlook. The excellence of one school does not translate automatically into the excellence of all schools. If it did, the snarls over the public schools' ineptness would be low and few. In the United States, the currently hyped market fix insists on a shotgun marriage between evolutionist Charles Darwin and capitalist Adam Smith that would give birth to schools that succeed and abort those that fail. But market driven schools already operate. A privately funded variant of voucher programs already operates in thousands of private schools, many with advantageous funding, involved parents, motivated students, and competent staff. Even with those advantages, most private schools find it difficult to outperform their public school counterparts. More important, they have produced no instructional innovations whose currency would rescue the presumed bankruptcy of the public schools.

Many fixes are promoted. Each has its acronym and its advocates, and each has its value. But each provides only a shard of the solution to a very old problem - the problem of a routinely productive educational system; a problem whose completely constructed answer still eludes us. Such a conclusion does not indict the public school, or the private one. It simply points to a continuing difficulty and to previous failures to correct it. The market fix, whether vouchers or some other, the tool fix, whether computers or some other, or the socialization fix, whether family values or some other, have not solved, and show no signs of solving, the central and brutal difficulty of an effective instructional system - how to teach so that all students achieve a predefined criterion of excellence.

\section{Science, Technology, and Organization}

\section{Successful Institutional Effort}

We can address the problem by asking a simple question, "Why is it that no society routinely educates all students to that level of excellence of which they are capable?". We are not talking about the education of an elite. We are talking about the education of craftsmen and intellectuals, of writers and bakers, of scientists and mechanics, of citizens and parents, of consumers and producers of economic and political goods. Such an accomplishment would equal the accomplishment of other institutional sectors of society. Why can't educational organizations produce repertoires of consistently high quality as routinely as airplane manufacturers produce high quality jet airliners? Each day thousands of flights occur in which aircraft lift tons of metal, cargo, and people into the air with only the occasional headline of an accident as a reminder of how rarely one occurs. Why hasn't the educational sector seen the equivalent advance as say the transportation field? Our own feet and the feet of other animals still transport us, but the twentieth century saw the beginnings of flights to the moon from the beginnings of flight for a few seconds over the sand dunes of a quiet sea shore. Or consider a commonly overlooked endeavor, the agricultural sector: The achievement of the American farmer is so great that we take for granted the presence of inexpensive and nutritious food in the market place, at the restaurant, and for much of the rest of the world. The efficiency of quality food production is so good that in the United States its required labor force went from a proportion that needed almost everyone, ninety-five percent or so three centuries ago, to about five percent today, just a small fraction of those who work. How do these other societal advances compare to those in the educational sector? The problems of producing jet airplanes would seem no greater than the problems of producing capable students. The problems of moving large numbers of people quickly and safely over land and sea and through air and into space would seem no less challenging than teaching them. The problems of feeding huge numbers of people cheaply and nutritionally would seem no less difficult than training them. We solved these problems, continue to improve on the solutions, yet persistently flounder in solving our problems of mass education.

What distinguishes these efforts and those made within education where exertions are as great? Obviously the difference is not due to lack of trying or intelligence or resources. The people in education work hard, master complex subjects, and all societies dedicate a substantial portion of their national income to educate their young. Wherein lies the difference? The difference resides in how effort, intelligence, and resources are packaged. What combination succeeds? The answer is, in a sense, in plain view. The successful blend of institutional effort ties together a science with the practical, effective technologies from whose principles they arise and these in turn are closely linked to organizational arrangements that appropriately deliver and execute that science and its derivative technologies. 


\section{Integration of Science, Technology, and Organization}

In the successful endeavors of any institutional effort such as those of agriculture, manufacturing, and transportation, we can observe the effective integrating of science, technology, and organization. One of the sectors previously mentioned, that of agriculture, illustrates the successful relation between the three factors. We entertain the romantic image of the solitary farmer looking at the sky, sniffing the wind, rubbing earth between thumb and forefinger. That still happens. But the farmer has buddies in the sky. Satellites with global positioning systems map to a few centimeters which portions of his land yield most. Meteorologists provide up-to-date weather forecasting over the internet directly to his personal computer. Sensors on his combines tell him which plants he should weed and which he should harvest. He increasingly adjusts to the variability of what he plants and therefore of the yield through feedback of the effects of herbicides, pesticides, and nutrients. He predicts plant outcomes against objectives to check plant quality, and controls processes to attain that quality. The farmer manages these science-based technologies in coordination with agronomists, extension agents, and farming cooperatives. So, in sum, what do we have? Two basic sciences, biology and physics, within whose powerful frameworks a number of subsidiary sciences operate such as agronomy and meteorology. These spawn and support sophisticated technologies operating through feedback that compares results with objectives. But note that more than science and technology is necessary. The extent of the knowledge involved and the reach of the skills required demand a team approach to the large-scale growing of inexpensive food. The farmer is but one member of a vast organization of a specialized division of labor. The science and the technology would not operate effectively without this division of labor. The agricultural miracle would be but a mirage of hopes, as is our current system of education.

Take any sector of society. Reflect upon it. Without effective technologies based on valid sciences operated through a complex division of labor whose diverse expertise is linked by proper organization, the sector would achieve little. The modern hospital organizes dozens of specialists. As exemplified by the operating room, many work as small teams that fuse their diverse repertoires for a given objective. Modern medicine would not be possible without modern organization. And clearly, the highly effective technology of large-scale industrial production came about through modern forms of management and organization. These resulted from innovations in the processing of materials, for example the assembly line, and in corporate governance, for example, the multidivisional structure. Whatever the area of endeavor, institutional success requires the powerful integrating of organization, science, and technology.

Technology, when effective, displays certain characteristics. What are these? To start with, reliability- that almost every time an effect is desired, it occurs. Who now can say that if a lecture is effective on one occasion it will be on the next? Or if a lesson plan succeeds at one time, it will at the next? And detectability - if an effect does not occur we can find out why, either by checking back against the science or through the internal feedback mechanisms of the technology itself. With educational technology, what now happens? Masses of students gather at prescribed times to take tests, and amid the welter of inferences justifying or explaining or condemning the results do any speculations unambiguously sort out the instructional techniques responsible for the results? No. What must we require, and why? For optimal operation, feedback mechanisms of any technology depend on consistent detailed real-time point-to-point information on the relation between outcomes and the operations that produce those outcomes. A productive instructional technology would match each student action with exactly that element of the instructional technique that produces an effect and would obtain the results immediately. It is a poor sort of technology that waits for years or months or weeks or even the next day to find out whether a technique worked or how well it worked. And that is the situation with current instructional evaluation. Not knowing what is happening at the time it is happening is like painting a portrait blindfold then coming back after a month, seeing it for the first time and trying to figure out why the outcome occurred as it did. Knowing the functional relation between technique and result provides the basis for innovation, especially when the proper organizational base takes advantage of the data and when analysis occurs within the technology's scientific framework.

Scientific principles initiate the baseline effectiveness and maintain the continual improvement of any technology, including the instructional one. Good science permits predictions that can be observed and checked out. Good science supplies relevant reasons for technical practices. Good science facilitates technological expansion into arenas not previously foreseen and the undertaking of problems whose solutions were not previously possible. We see the effect of good science in such endeavors as the engineering of the human genome or the exploring of the planet Mars. With rare exceptions, we suffer from the absence of good science in education. Without good science we work with hand-me-down nostrums useful only in very circumscribed circumstances. All instructional techniques become local. What is accomplished depends upon art and accident.

But equally important as effective technology and good science is the social union by which and through which a technology operates.

Organization is often overlooked when discussing science and technology. Subtle and esoteric sciences and exacting and complex technologies require skilled repertoires; a variety of them. But more than varied skills are required. People work together to accomplish what they could not do separately. In short, they organize. They coordinate practices 
so that different skills complement each other. To work together with the technology applied to a given effort, from auto making to open heart surgery, from producing planes to farming foodstuffs, such complementarity of skills must be sequenced and integrated in the correct order. Infrastructures within the organization sort the correct collection of skills, for example in industrial firms the infrastructures of finance, marketing, and production, among others. These infrastructures must suit the type of technology in use. Some technologies demand a hierarchical structure; others demand a team-based operation. Infrastructures that fit their technologies constitute a good organization. If a technology changes so also must the way people organized to deal with it. A new form of technology calls for a new type of organizational structure.

\section{Education and the Triad of Science, Technology, and Organization}

In looking at the interacting science, technology, and organization components within the arena of education, we come to an inevitable conclusion based on its comparative record of success in relation to other institutional sectors. The educational sector requires an overhaul of the triad of the current science, current technology, and current organization, and in overhauling these components, as important as science and technology are, so is organization. We need to change the science and to change the technology. As well and appropriate to these changes, we need to install a completely new organization. We need to innovate not only in one component, but in all three. The prevalent science, the typically encountered instructional technology, and their accompanying organization have not and can not handle the problems of mass education.

\section{Science and Education}

The current underlying behavioral sciences for education are driven by a particular assumption-that of an inner causal agency. The assumption forces a focus on the person. Inside a person, an entity is said to direct and cause that person's behavior. The entity may be a personification of the individual—an ego or self or mind. Even behaviorists bring in that agency. Keller in his Personalized System of Instruction, PSI, talks about self-paced instruction as if a self paced the action through the instructional modules. A more updated version of the inner causative agency makes it a structure or a process, cognitive for example. But there is still an entity that does the thinking or remembering, that perceives events and interprets them, that has memory with which to recall its past, that inherits linguistic ability to generate sentences and decide what to say, that is receptive and expressive about language. It is so ubiquitous we take it for granted. Our language is at one with that notion: We and I determine what we do, and You and They, He and She, determine what other people do.

But almost all of the analysis of what goes on within the individual is inferential. For much of current cognitive science, the action observed merely gives an opportunity to get at the real stuff. From the action observed, that real stuff must be inferred. Clearly, the danger in this sort of analysis is circularity. It becomes agencies all the way back until an inscrutable one is reached. Alternatively, a sideways reductionist leap may be made, and it is said that the cause is nothing more than left brain synaptic changes or the molecular configurations of proteins, or some such. Agencyism, however, is a dead end. Reductionism inappropriate. Neither causal alternative is helpful to the teacher in the classroom and to the designer of an instructional system.

It should be understood clearly that the argument advanced here is not against inference. There is nothing wrong with inference. All scientists engage in it and all sciences accommodate concepts based on inferences. Many astronomers have long assumed that our solar system is not unique; that planets revolve around other stars. With better techniques and instruments and hard observational work, that assumption has paid off. Over a hundred exoplanets have been discovered. One of the four planet detection techniques measures shifts in the star's spectrum as light is pulled away or pulled towards us by a planet orbiting that star. Of course it could still be argued that "something else" might produce the shifts and that saying it is a planet is merely an inference. But direct infrared imaging of planets is now planned. In the sciences, eventually either accurate prediction or direct observation or practical results must affirm what is inferred. With respect to these criteria, what is the record of the prevalent agency-infused science underlying education? It is dismal. That is why much of it has retreated into reductionism-to physiology, to genetics, and to computer-based metaphors.

The evidence for the prevalent circularity based on agencyism is sterility of results. Millions of words have been spoken and written about instructional technology, but with an outcome of only a few practical results-essentially by accident. A few inspired folks like Montessori had some success with their instructional techniques. But when people adopt the Montessorian technique, they duplicate Montessori's model. They do not generate new techniques from a powerful science. We see such barren "innovation" not only at the elementary level, but at the university level as well. As Morris Bishop (1970, pp. 265, 268) dryly concludes,

"The word universitas means no more than "the corporation." Its first recorded appearance is in a letter of Pope Innocent III in 1208 or 1209. The first university was at Salerno in Italy, followed by others at Bologna, Paris, Montpellier, and Oxford ...

The students assembled for class in rented rooms or halls, or in churches. They sat on hard benches or on the 
straw-covered floor, taking notes with styluses on wax tablets. The professor read some standard text, then expounded and commented on it, then, usually permitted criticism and discussion by the students. Pedagogic methods have not changed much." In education, this agency-infused causality has been in place for centuries. Not much science and little useful technology has resulted.

If we banish the indwelling agency, what are we left with as cause? We are left with physical or biological or behavioral events. There are no other kind. We banished agency from the physical analysis of phenomena. Boreaus no longer makes the north wind blow nor does Neptune cause storms at sea. At a more subtle level, notice that when Newton talked of apples and moons, he was not analyzing their qualities; and it is a waste of our time to analyze the qualities of someone's presumed mind. When Galileo rolled balls down inclined planes, he analyzed the relation between angle and motion. He was not trying to analyze where the ball stored its movements anymore than we should be trying to analyze where people store their behavior. Though agencyism has been mostly expunged from biology, the last remnant of a struggle continues there. Molecular biology vanquished the final vestiges of vitalism from biology, but intelligent design, and thus by inference an intelligent designer, is offered as an explanation as the alternative to natural selection for the facts of evolution. Though much of this agency struggle is no longer internal to biology (unlike that of the behavioral sciences), but driven by external cultural forces, part of the problem has to do with the form of explanation that Darwin offered. It is a form of explanation characteristic of the science that should underpin education.

The predominant form of explanation primarily in the physical sciences, still prevalent in the biological ones, and common in everyday life is push, result. An antecedent cause produces a subsequent outcome. Everyday discourse, as well as weighty tomes, insist that for any action, something had to determine or someone had to decide beforehand what would occur. But what if the effect were due to something that happened after the action? The notion is counterintuitive. Yet this was Darwin's great insight at the level of species change. And it was Skinner's at the level of individual behavioral change. Explanation can occur, of course, by observing events that come before what happens. But we can also provide an explanation by observing events that come after the action of interest. All the demurrers about inference still stand, but now apply to causes subsequent to the activities of interest.

What about the individual? He or she is a location of action, like Galileo's ball, but not the reason for the action. The current situation is also a location. It is the interaction between the two that produces the characteristics, the properties, of actions. The focus now becomes the relation between actions and other events. The analysis and the explanation starts with the events that come after; though eventually, those events that come before are considered in relation to these subsequent events. But our analysis must take a step further, for the effects are not even on the actions. It is on their properties. What happens to these properties of actions becomes contingent upon their consequences. These determine the values of their direction, their frequency, their latency, their duration, and any other properties that can be analytically isolated. Such an analysis is not psychic, not physicalistic, not physiological, but an analysis of contingency-based relations, under the rubric of the science of behaviorology, formulated upon the feedback reciprocities between properties of actions and postcedent and antecedent events functioning as independent variables (Vargas, 1996a). Skinner's work (1938/1991) originated the science. It leads to a unique instructional technology.

\section{Technology and Education}

The basic etymological notion of the word, technology, is techniques; "techne" from its Greek origins, meaning a systematic way of doing things. So the word here does not refer to tool technology-movie projectors, television, computers, the internet, and the like. These are mass communication tools. Much of the innovation in education has been the adoption of these tools. As early as the first part of the 20th century Edison claimed that movie projectors would revolutionize education and solve our instructional problems. The same claims were made for the computer. Now it is heard about the internet. These are tools from the physical sciences. They are useful. They reduce the per unit cost for reaching more people. But they are not innovations in instruction. The instructional gains from these tools, for example computers, have been minimal. They do not by themselves improve the effectiveness of instruction. Effectiveness depends on the instructional techniques, the process methods, designed for those tools to deliver. Process quality dictates what the tools accomplish. As programmers and instructional designers say, "Garbage in, garbage out". The quality of the tools - the projector, the computer, the internet-depends on advances in the physical sciences. But any effective instructional process must be based on the behavioral sciences. Instructional technology deals with what people do, say, think, and feel. What it accomplishes with these aspects of actions defines the quality of an instructional technology's process, and those aspects vary considerably among people.

The critical characteristic of all student actions is their variability. The variability of repertoires with which education must contend presents its central problem. It is this variation that should constitute the all-absorbing focus of any instructional technology. No matter how small the class, each repertoire of each student varies in each of the cardinal dimensions that must be instructed: knowing, solving, and creating. Imagine two students in front of an 
instructor. At any point of a lesson one student knows more than the other. Or if these students know more or less the same, one solves more easily a problem with the material both know equally well. And of course creatively they will differ. Furthermore, such differences will vary at different points of the instructional sequence with each of the students involved. Even if an instructor faced only one complex repertoire, it varies over time in desire, attentiveness, performance, and so on.

The luxury of teaching only two students, much less one, rarely occurs. Instead instructors face the problem of instructing tens, hundreds, even thousands of students in the same material at the same time. Mass education has raised the problem of variability to a crisis level. Variation should be the target of our instructional models. It raises problems that cannot be solved with the current instructional model, and that model's track record is not the only evidence of its inability to succeed.

Take a quick look at the present model of delivering instruction. It is basically a model from the physical sciences. The teacher transmits information. (The teacher functions as a transmitter.) The student receives information. (The student is a receiver.) The student processes this information. (The student's processing was at one time a rough analogue to a telephone exchange system; now the metaphor for processing is that of the computer's-input, storage, retrieval, process, and output.) The presumed explanation of performance is in how the student does the processing. It is asserted that the student decides to act, comprehend, store in long or short term memory, and so on. These are the familiar expressions of the agency-infused underlying science. The current instructional technology ignores the variation in behavioral properties for the predicated essentialist nature of the student acting as a receiver and processor. The presentation technology model follows the agency framework exactly. But merely presenting "information" does not work. Even at universities with the most sophisticated experts on their faculty and with extraordinary entrance standards for their students; even at places like Harvard or Oxford or the Sorbonne, only a small percentage of students excel; most get by. A substantial fraction of university students never finish, regardless of the country or higher education system and whether public or private. This presentation technology is a technology as simple as can be obtained. A person talks, others listen. A person writes, others read. A person demonstrates, others watch. Presentation technology has been around since we have had education, and certainly for the university since its beginning in the high middle ages. It is easily designed for whatever delivery device is currently favored, such as the internet, and for the mythical student, such as the "average" one.

Presentation technology works like prefit tailoring. It is like asking a tailor to come up with clothes that would fit a hundred students, and that tailor cutting and sewing the same set of clothes based on a conjectured build of a typical student. Most students would not fit into the precut outfit. Students could be asked to recut and resew until off-therack clothes fit; that is what is done with homework. To address their individual shapes and forms, one-size-fits-all tailoring would not be done with their bodies. It should also not be done with their repertoires. We need an instructional technology that takes into account the variability in repertoires.

The technology that takes into account variability is a contingency-based technology. Given a history of both activity and circumstance, the descriptor contingency-based makes clear that any activity, inner or outer, is contingent upon the circumstances, body and setting, in which it occurs. Behaviorological science provides the operating maxim: actions and their differing properties are the focus of effort, not students. (Students are the aim of ethical effort, not technical manipulation.) Each action carries properties which provide an opportunity to alter them according to instructional objectives. Two basic strategies emerge: either the form of the action is altered by altering its properties or the controls under which an action occurs are altered. Drama coaches change the effect of speech by changing how loudly or how softly, how quickly or how slowly, and so on, text is vocalized. In other instructional situations, properties of an action are not addressed, only the controls that evoke it. Note that in multiple-choice tests the same simple motionpicking an answer by marking or pressing-is involved under differing stimulus controls that typically are textual. Of course, much instruction merges both types of strategies, altering both the action form and the stimulus features to which it must respond, such as in teaching how to play the guitar. Though complexity of the instructional task is compounded when sequencing various actions forms and various types of controls, the same basic principles are involved. For example, frequency is a common property that is altered by changing the probability of making a response (or a set of responses) within a given unit of time. Dealing with the frequency of actions provides alternative techniques for dealing with presumed causal qualities currently called "motivation" and "memory". And so on with each of the properties of actions and situations. In all these issues, situational consequences and circumstances drive the pattern and energy of actions, and change the particular action form given by its matrix of property values. The complexity becomes enormous; a complexity barely touched.

This complexity now begins to be addressed by an increasing number of contingency-based instructional technologies, and though many and diverse their process characteristics allow a rough and ready classification. We can classify the techniques of these instructional technologies in two general groups, perhaps three. The first is shaping. Each behavioral change is done a bit at a time. Outcome and feedback dictate the next stimulus feature and action 
property of an instructional program. Shaping by and large depends on consequating the shift in a given direction of a particular property of an action. (For an interesting discussion of this matter, see Mechner, 1995). The second is saltational. Such saltationist technology takes advantage of the fact that each so-called action and so-called stimulus is really a confluence of properties that overlaps with properties of other actions and stimuli. Induction occurs. And with the right techniques, such as those of equivalence relations and of joint control ( $\mathrm{Tu}, 2004)$, induction allows new action forms to emerge suddenly. Solutional and creative behavior can be taught. The third type, techniques like fluency training and positive care, address topics traditionally called "memory" and "motivation". As a subset of contingencybased techniques, precision teaching particularly promotes frequency techniques to enhance fluency (Calkins, 2003). But in any given contingency-based technology, for example that of CABAS (Comprehensive Application of Behavior Analysis to Schooling, Greer, 2002) or those of Pryor (1999), instructional designers blend together many of the techniques of the different categories. (Or if they do not, it is urged that they do so. See for example, Vargas, J. S., 2003). Other programs - such as Morrow's Applied Behavior Consultants model (Morrow, Terzich, and Williamson, 2004) and Bondy's (2002) PECs system that specialize with a particular population of students such as autistic children-draw heavily from contingency-based techniques operating within the framework of Skinner's analysis of verbal behavior (Skinner, 1957/2002). Over time, the characterization of contingency-based instructional technology by its current classes of techniques will of course alter.

A further characterization is quality control. Contingencybased teaching technology inherently is a quality control effort. The science upon which it is based emphasizes the feedback effect of consequences and the reciprocal feedback between these consequences and features of the situation and the activity with which those consequences interact. Feedback in conjunction with objectives and standards binds quality control into the technology. Currently that is not the case with traditional instruction. For example, presentationbased instruction obtains a record of performance that is apart from the events responsible for that performance. Traditional instruction tests students after the learning event. The crucial relation of the actual teaching and learning process is not observed. What went on while the student learned? How were actions being changed? What specific action occurred and to which particular events and at what rate? Tests record an effect, not how that effect came about. Current instructional evaluation focuses on a molar effect, an overall test score, instead on the specific molecular aspects of the instructional arrangements responsible for the differing parts of the student's performance.

Contrast a contingency-based instructional system: It provides immediate feedback on the repertoire as that repertoire changes. It observes and records the relation between changes in an instructional condition and the behavior encountered. It separates the production (and assessment) of performance from a ranking of performance. This latter factor is quite important, and an overlooked feature of evaluation. If each part of a repertoire is taught successfully then the end result is known already. The performance is at 100 percent successful criterion level. Ranking in what is known becomes irrelevant. The issue of grade inflation vanishes. Grade inflation assumes a built-in failure to teach. It also assumes that the larger portion of students are not capable of doing well. Grade inflation is made synonymous with quality inflation. But would anyone accuse Apple Computer of quality inflation if all its computers operated, by whatever means measured, at a socalled "A" level? The president of Harvard University becomes indignant at the high grade levels and honors of recent Harvard students. A good deal of noise, emitted at other campuses as well, is made about a return to standards. It never seems to enter the considerations of this president, or of others, that perhaps the Harvard faculty is teaching better (or despite the presentations, the students are learning more). It does not occur to him, or to others, because outcomes have taught him and others that traditional instructional technology can not increase the quality of repertoires beyond a certain level for any set of students, therefore grades that imply otherwise are suspect. Given the current instructional technologies, people expect, they even demand, that a certain portion of students fail, or at minimum not be judged as excellent. And there is another side to this dismal coin: If the students are good enough, then not achieving excellence implies a build-in failure of skill on the teacher's part.

An additional and important characterization of contingency-based instructional technology is the specific control over instructing behavior. Any instructional technology must also improve the instructing repertoire. With the current presentation model workshops and circulars encourage the instructional nostrums of the day, but these provide little help as evidenced by the "same old" instructional quality after the circulars are read and the workshops attended. But for instructional quality to rise, the immediate dynamics of the instructional system must affect instructing behavior. Each contact between the instructional system and a student action must be accompanied by contact with instructing activity. What the instructor does must be contingent on the outcome of student-instruction interaction. If instructors do not intimately know what happens during the instructional process how can they innovate rationally? On what basis do they increase the chances of improving the student's performance? How can teachers succeed when they do not know what steps to take in order to succeed? In sum, in contingency-based technology the following dynamic ensues: Quality control is built in since it is based on the three constituents of quality control: objectives, standards, and feedback. Detailed feedback, in the form of 
the specific relations between action and stimulus properties and the consequences of contingent outcomes, provides the means of achieving objectives at given standards. Without this informative interaction, accountability arrangements only end up punishing teachers. Standards are necessary, but they require a means of achieving them.

\section{Organization and Education}

New ways of doing things, including those of teaching, entail different coordinative and communication arrangements. Contingency-based instructional systems call for a radically different organization than now exists. The role of a teacher is not simply to present. The role of an administrator is not simply to manage. The role of a student is not simply to learn. At an ethical level, students, teachers, and administrators are partners in a common enterprise. At a behavioral systems level, each set of partners' actions tie tightly to the others. For example, administrator actions in traditional education organizations are often divorced from the immediate momentto-moment intimate effect of technology procedures. Only output affects them, not instructional process. In contingencybased instructional technology, administrators as well as teachers contact the current effects of the instructional process on student performance. Knowing what produces an outcome puts administrators in a better position to allocate instructional technology resources and to work out this allocation with the teachers. The profound change in both administrator and teacher roles reflects the radical change in the apportioning of teaching responsibilities.

Teaching responsibilities are entailed by teaching activities. A contingency-based instructional system entails a diverse, complex, and enormous number of instructional activities. This more sophisticated technology clarifies the operations already involved in varying degrees, mostly neglected or trivialized, in the current attempt to teach. One operation involves those techniques that will actually change a repertoire. Another operation involves the evaluation of the instructional techniques. A third involves the means of delivering instructional contact-by computer, or video, or internet for example. A fourth operation, logistics (typically not undertaken by an instructional staff), individually tracks multiple repertoires through multiple instructional contexts. And fifth, last, and certainly not least, a separate operation considers what is to be taught.

One person cannot handle all of these operations well. Each of these characteristics of the instructional process demands its own expertise. As in farming, doctoring, or manufacturing, the improving of repertoires so that society values them demands a wide array of expertise. To succeed, instruction demands expertise in subject matter content, in instructional design, in evaluation and quality control techniques, in logistical management, and in presentation modes. What flows through any school-primary, secondary, and university-are behavioral repertoires that the educational organization transmutes and that in so doing gives them value. To deal effectively with this behavioral flow demands an appreciation of the mutual reciprocity of actions and instructions within shifting contexts.

This expertise must be organized to work together. It occurs when experts that complement each other work as a cooperative unit. The various experts operate as a team, an instructional systems team. Not only the content expert, the traditional role of the teacher, is a teacher. All of the various experts are teachers. The logistics expert is a teacher. The evaluation expert is a teacher. The media expert is a teacher. The instructional designer is a teacher. Without each, the job could not be done. No one role is greater than any other. For example, to assess what is to be taught is an important as what is to be taught or how it is to be taught. Becoming a team player, however, requires organizationally subordinating the traditional role of the content expert.

But does being a member of an instructional systems team lower the impact of the subject matter teacher? Does being a team member sharing responsibility for teaching diminish the role of the subject matter expert? And does being a member of a teaching group limit the influence of the subject matter expert? Though it might seem so, the answer to each question is "no". Being a member of a teaching team enhances that expert's role, impact, and influence. Content experts would now have a good chance of being effective with their subject matter. Currently the teaching burden rests on that one person-that subject matter expert. He or she cannot do it all. The expertise to do it all simply is not there. Even if we entertained the implausible scenario that one person had all that expertiseknowledge of the basic science from which the techniques are drawn, knowledge of the various aspects of the process technology, knowledge of sophisticated quality control techniques, knowledge of various media such as television or computers and how to program them, and knowledge of logistics and how to manage them-that one individual does not have the time. When a book is written, the author writes it as a content expert. Authors do not engage in the marketing, designing, illustrating, printing, and all the other activities involved in getting that book out to the public. If they attempted to do so, they would end up doing more of that than of writing. A wide array of different experts staffs movie making, and not only actors, directors, and photographers. Movie credits reveal an extraordinary division of labor. Finally, a last and important point, at the university level subject matter experts are not hired for their teaching skills. They are hired for their expertise in physics or mathematics or music or literature or sociobiology or anthropology. Rarely do they exhibit the effort in learning the immense subject matter known as pedagogy. And they should not be interested in doing so, nor required to do so. It is a full time job being a good anthropologist or geneticist or historian, and it takes more than the typical average workweek effort if these specialists wish to make a 
breakthrough in their fields. In the university, teaching should be delegated to those interested and skilled in teaching.

Moving to a restructured organization grounded on a complex team-based division of labor means that the organization becomes the "teacher". In contrast, the current instructional organization resembles a teaching mall that houses a scattered array of individuals doing their best, leaving behind perhaps a Mr. Chips legacy but not an institution that functions more effectively. The recommended structural shift contains profound implications, for organizations share certain properties, regardless of the institutional sector of their operations. In the educational sector as well as the industrial or military or any other, organizations learn. As Chandler (2002, p. 2) points out, "Individuals come and go, but the organization remains. Thus, in modern industrial economies the large firm performs its critical role in the evolution of industries not merely as a unit carrying out transactions on the basis of information flow, but, more importantly, as a creator and repository of product-specific embedded organizational knowledge."

What can be said about industrial organizations, as organizations, can be said about any organization. The current structural characteristics of educational organizations, whether primary, secondary, or university, do not facilitate, perhaps even not permit, their acquiring cumulative knowledge in their teaching function. For example, whatever level and domain of educational organization none contains a quality control unit obtaining performance data from instructional systems throughout the school, evaluating these data, and feeding them back to instructional teams for more effective redesign of instruction. No one can say of any educational organization, whether James A. Garfield High School or University of California at Los Angeles or Lafayette College, that it is three or four or whatever times better in its teaching function than it was, say, fifty years ago.

The organization of teaching teams within the primary, secondary, and higher education levels would differ according to the missions of the educational institutions involved. For example, aside from public service, the university has two great missions: that of research and that of instruction. It must produce new knowledge and it must produce new repertoires. Although much lip service is given to teaching, current university structure favors subject matter by organizing their faculties in departments such as art, biology, chemistry, and so on. Instructional systems and their teams would require a new arrangement. There would be two faculties: those expert in a subject matter and those expert in teaching. The university's faculty would thus be bimodal. This bimodal faculty would be structured to facilitate research and instruction, and thus would be organized into instruction centers and research centers. Research teams would operate out of the research centers and instructional teams out of the instruction centers. Researchers and instructors would go back and forth on each other's teams depending on interest and need. An earlier article of mine summarized a few of these organizational characteristics (Vargas, E. A. 1996b, pp.182-183):

The new organization structure emphasizes flexibility, decentralization of control, and formal dissemination of information from critical client groups. The design, production, management, and redesign of instruction by instructional system teams implies a cluster-type organization - a collaborative effort of teams of people whose size, members, and jobs may change. ... Hierarchical levels of control are de-emphasized. For example, coordinators of instructional systems teams may interact directly with the vice president for instruction. Information and documentation teams interact directly with various sectors of the public, the professions, and the political sphere such as government. These information and documentation teams directly access demographic, economic, and other data vital to the university's teaching, research, and service missions, and after analysis of these data, move them to appropriate sectors of the university.

The specifics of each organization's structure within any educational level would depend on a host of factors such as internal culture, type of student, level of funding, and outside social pressures.

\section{Social Considerations and Cost}

An entangling factor in the complex interplay between science, technology, and organization is the social milieu in which this triad of elements engages in its drama. The conditions, values, and ethics of a society may dictate a specific thrust in science or the employment of a prevalent form of technology or encouragement for a particular type of organization. Or their opposite. Wartime effort accelerated the understanding of nuclear fission. The samurai warrior culture of Japan resisted the use of guns. Fundamentalist religious groups contest research with stem cells. Regardless of greater achievement in instruction, people inside the university will find it difficult to accept an organization in which content experts are not the primary teaching faculty and within primary and secondary schools team arrangements may be resisted because they apparently appear to destroy the authority of the principal. Simply because a better way of taking action appears plausible does not mean it will be accepted, much less encouraged.

These considerations often play themselves out economically. An innovation may not be hazarded because the budget does not sustain the risk. But not infrequently, fault-finding disguises itself as fiscal prudence. "We can't do it because it would cost too much", or the more easy rationale, "How do we know the return will be worth the cost?" These questions are pertinent. Certainly before a risk is taken, any 
reply to the second objection can only be predicated, guessed at, theorized over. It cannot be factually answered.

So a relevant question of the triad model is: Would it cost more? Of course it would. Does it cost a lot to get a new jetliner in the air? From designing to manufacturing, the cost runs into billions of dollars; much more than it cost a couple of bicycle makers to build the first airplane. Take any example where quality is imperative, reliability is absolutely necessary, complexity is inherently part of the process and of the product, and where all these considerations must suit a large clientele. The same escalation of cost occurs. But something else also occurs when success follows undertaking of the outlay: downstream enrichment benefit to a society, to the institution, to an individual. Factories for computer chip technology and for producing computers cost billions. But all benefit from the results. Productivity grows in all sectors of an economy and all goods cost less on a per unit basis. And as individuals, we now carry around the equivalent, twenty years past, of a mainframe.

Who can afford the innovation of the triad model? Countries outside the United States may be the first; mostly countries improperly called Third World countries. The label for these countries, "Third World", is a misnomer. Such a label hides the complexities of their economies and their social structure, even their ambitions (Friedman, 2000). The label also hides the economic and social realities of so-called "First World" countries. All countries have their mix of First World and Third World economies and technologies. It is the mix, and the ratio of what is mixed that matters. The United States has more than 40 million people without any health coverage-roughly one in seven since it has a population of almost 300 million. Many of these people trade off costs of provisions for prescriptions. Many go without both food and medicine. Many live in substandard housing or are homeless. When we say "many", we are talking millions here. A third world economy, society, and population exists in the U.S. bigger than in many so-called third world countries.

But how about the situation in education? As Bracey (2002, pp. 146, and 148-149) points out in the following two quotes, in California, one of the richest states in the richest country in the world,

"The American Civil Liberties Union filed a class-action suit on behalf of a number of poor districts located throughout California. Claire Cooper of the Sacramento Bee reported that depositions in the case contained "snapshots of filth, chaos, and desperation," such as these:...

- "Rats in cafeterias, one carrying fruit in its mouth, others scurrying around a bread rack.

- Chemistry labs with no chemicals.

- Literature classes without books.

- Computer classes in which, according to one student, "We sit there and talk about what we would be doing if we had computers."”,
And in Louisiana, with some of the largest oil and gas reserves in the richest country in the world, a pair of education professors "went back to the classroom for a year, teaching in a poor rural school ... Their school had "no library, no playground equipment, no hot water for washing hands, no art teachers, no counselor, and one toilet for 72 faculty and staff. We began our year with no maps, one globe, a shortage of textbooks, dictionaries from 1952, malfunctioning heating/cooling systems, and a healthy supply of cockroaches and other pests." The students the Johnsons [the education professors] taught had no trouble sounding out a word like "waitress" but had no idea what it meant- they had not been to restaurants that use them." Symmonds (2002, pp. 124-125), the executive director of the Campaign for Fiscal Equity, sums the situation well, "Among industrialized nations, the U.S. is unique in having an educational system that provides the least resources for students with the greatest needs". A matter of priorities, isn't it? Some countries put a lot of their resources into the leisure and military industries, others invest elsewhere. Finland's education ministry budget is a lot larger than that of the defense ministry. Costa Rica has no military, but it heavily supports its ecology programs. Furthermore, in countries outside the United States, many institutional sectors, such the military, are not as expensive. The economic pie in these countries may be smaller but more remains for education, if that is the priority.

Any consideration of cost always involves social policy, considered in light of current resource allocation and over long-term consequences. In the long run, the underlying solution of educational costs is demographic. As August Comte, the founder of sociology put it, "demography is destiny". If the population rate is lowered so is the burden of mass education. The same number of educational dollars or pesos or yen go further as there are more available on a per unit basis. The per unit basis introduces the other aspect of cost: its investment characteristic. Cost by itself is a meaningless figure. It can only be assessed in terms of its return. The current return wastes human resources both individually and socially:

- "Students committing suicide when failing university entry exams.

- High crime rates by the unskilled.

- Poor understanding of the political process.

- Large drop-out rate between primary school entry and high school exit.

- About half accepted into higher education ever leave with their degree."

Those are a few of the dismal facts. Many others are just as dismal. Such outcomes have been with us from the beginnings of mass education. They need not continue. Their cost is higher than any radical new solution. Effective instruction is possible, but it requires a solution unlike any other previously attempted even if immediately more costly and hazardous. 


\section{Conclusion}

The relationship between science, technology, and organization at first appears to be straightforward. A set of scientific principles supplies an understanding of a given set of phenomena well enough so that practical techniques - that is, a technology, or when more rationally sophisticated, an engineering-derived from those principles can control and predict that phenomena for everyday use. To wield these techniques, skill is necessary. When the enterprise is complex in its operation, the skills are many and varied. To mesh these diverse skills effectively, they must be controlled and coordinated. Organizing them becomes necessary. The scale of operation may be large or small, but organization of mixed skills expressed through a division of labor becomes necessary as the scale of difficulty, of size, and of effort increases.

Clearly, an operation of intricate complexity could be managed by one person. Though best carried out by a team of specialists-anesthesiologist, nurse, surgeon, and so onin an extreme emergency an operation that opens up the human body could be conducted by one intrepid individual. In The Doll Maker, Harriet Arnow (1954/1972, p. 21) describes the improvised surgery by a Kentucky hill woman, who slices her child's throat to prevent it from dying from croup,

...The fingers of her left hand moved quickly over the cut skin, feeling, pulling the skin apart, holding it, thumb on one side, finger on the other, shaping a red bowed mouth grinning up from the child's neck...

The knife moved again, and in the silence there came a little hissing. A red filmed bubble streaked with pus grew on the red dripping wound, rose higher, burst; the child struggled, gave a hoarse, inhuman cry...

She gently but quickly wiped the blood and pus from the gaping hole, whispering to the child...

But no one person could carry out all the tasks necessary to open up space, to implant an artificial heart, to mine the ocean floor, or to teach tens of thousands of students thousands of subjects from art to zoology. The impossibility of any one person mastering more than one or two subjects is well recognized in the increasing array of content experts handling the vertical integration of subject matters. Such vertical integration-from basic arithmetic to advanced calculus, say-recognizes the increasing complexity of a verbal repertoire. Another kind of integration is also necessary. Overlooked at all levels of education, primary, secondary, and higher, is the necessary horizontal integration of the complex components of the instructional processdesign, quality control, and so on-and the reciprocal feedback that occurs (or should) between them and science and organization.

Independent of considerations of scale of difficulty and of effort, in an apparent natural sequence, science foundations provide the rationale for technologies and these in turn set the requirements for the skills to operate them which then set the stage for the structure that best facilitates their operation. But historically, as well as currently, the interaction between science, technology, and organization has not been, and continues not to be, such a straight line outcome. A tangled interplay reverberates between science, technology, and organization. Science may evolve from craft as easily, or with as much difficulty, as craft from science. The analysis of natural selection in evolution borrowed much from the work in animal husbandry while on the other hand, genetic engineering depends considerably upon molecular biology. Technology can drive the development of a science, as increasingly powerful telescopes did in astronomy. And without the proper organization to execute them well, both science and technology may languish. Building the atom bomb and working out its physics, was due as much to an achievement in organization as it was in science and technology. In the interplay between science, technology, and organization, any point in their mutual effect from which to state a causal analysis is as good as any other.

Such an analytic given does not mean that one neglects or overlooks or excludes any of the three required components in putting in place a contingency-based instructional system. Any attempt to initiate a contingencybased instructional technology will require setting it within the proper organizational structure and designing it from the proper scientific foundation. What the "analytic given" does mean is that in how such placement is done no set recipe as to how to proceed can be offered. Each educational organization presents its nuances of culture, of people, of resources, of all the myriad characteristics that make it a unique entity. Those most immediately in contact with the problems of integration can best solve them.

\section{Summary}

We recap the following fundamentals. For optimal success, in any large scale enterprise the organization of the division of labor must fit the technology through which that enterprise achieves its mission. This is as true in the large scale enterprise of education as those, for example, of agriculture, manufacture, and transportation. As with other institutional efforts that show success, educational technology must tie directly to a pertinent science and to a fitting organizational structure.

We can summarize further. Solving the problem of teaching well requires an overhaul of our educational system with three concurrent endeavors: One, a new technology of instruction, a contingency-based system of instruction, that becomes an engineering enterprise with practices derived and dependent upon suitable scientific principles; two, a relevant science that reflects and encapsulates a different understanding of behavior; three, a process-based organization designed around the control and coordinative 
necessities of an instructional division of labor based on teaching teams. Each part of the solution requires the others.

Such intimate dependency leads to our final summation. Science and technology and organization complement each other. No part solely determines the outcome of the other two; instead each affects and in turn is affected by the others. A complex interplay of feedback ensues. Emphasizing the importance of their dependent interplay, however, does not underplay the effect of power on an educational organization from other sources, for example, business, political, or religious special interests. But their impact on teaching quality can best be judged once we take into account how within the educational enterprise to bind together science, technology, and organization.

\section{References}

Arnow, H. (1954/1972). The doll maker. New York: Avon Books. Bishop, M. (1970). The middle ages. New York: American Heritage Press.

Bondy, A. (2002). PECS and verbal behavior. In L. Frost \& A. Bondy (Eds.), The Picture Exchange Communication System (PECS) Training Manual, 2nd Ed.. Newark, DE: Pyramid Educational Products.

Bracey, G. W. (October 2002). The 12th Bracey report on the condition of public education. Phi Delta Kappan, 84, 2, 135-150.

Calkin, A. B. (2003). The course of precision teaching. European Journal of Behavior Analysis, 4, 87-96.

Chandler Jr. A. D. (2002). Inventing the electronic century. New York: The Free Press.

Donne, J. (1633/1991) Satire 3, The search for true religion. In Emrys Jones (Ed.), The new Oxford book of sixteenth century verse (pp. 629-631). Walton Street, Oxford: Oxford University Press.
Friedman, T. L. (2000). The lexus and the olive tree. New York: Anchor Books.

Greer, R. D. (2002). Designing teaching strategies. New York: Academic Press.

Mechner, F. (1995). Learning and practicing skilled performance. New York: The Mechner Foundation.

Morrow, J. E., Terzich, B. J., \& Williamson, P. N. (2004). Preliminary outcomes of a school based behavior program for children with autism spectrum disorders. Manuscript submitted for publication.

Pryor, K. (1999). Don't shoot the dog: The new art of teaching and training (Rev.ed.). New York, Bantam Books.

Skinner, B. F. (1938/1991). The behavior of organisms. Cambridge, Massachusetts: B. F. Skinner Foundation.

Skinner, B. F. (1957/2002). Verbal behavior. Cambridge, MA: B. F. Skinner Foundation.

Symonds, W. C. (2002, October 14). Closing the school gap. Business Week, 124-125.

Tu, J. (2004, March). The role of joint control in the manded selection selection of responses of non-vocal children with autism. Paper presented at the 16th Convention of the International Society for Behaviorology, Boston, MA.

Vargas, E. A. (1996a). Explanatory frameworks and the thema of agency. Behaviorology, 4, 30-42.

Vargas, E. A. (1996b). A university for the twenty-first century. In J.R. Cautela \& W. Ishaq (Eds.), Contemporary issues in behavior therapy: Improving the human condition . New York: Plenum Press.

Vargas, J. S. (2003). Precision teaching and Skinner's legacy. European Journal of Behavior Analysis, 4, 80-86.

Received September, 1, 2004 Accepted September, 15, 2004 